seizures (Proc Soc Exp Biol Med. 1966;123:968), refer to WF Petersen's extensive treatise concerning effects of weather on disease and the relation between meteorological disturbances and onset and severity of epilepsy (1934). Also, Tille D had observed a higher incidence of febrile convulsions related to cold weather fronts (1950).

\title{
NON-BENIGN FAMILIAL NEONATAL CONVULSIONS
}

An electroclinical pattern characteristic of benign familial neonatal convulsions is reported in two neonates with non-benign seizures treated at the Miami Children's Hospital, FL. Ten seizures recorded by continuous videoEEG telemetry began with generalized tonic posturing and diffuse attenuation of EEG activity. Bilateral clonic movements that followed were accompanied by repetitive sharp waves or spikes. None had a family history of seizures, and one patient followed for 5 years had speech delay, hypotonia, hyperreflexia, and autistic behavior. The cause of seizures was undetermined. (Alfonso I, Hahn JS, Papazian $O$ et al. Bilateral tonic-clonic epileptic seizures in nonbenign familial neonatal convulsions. Pediatr Neurol April 1997;16:249-251). (Respond: Dr Alfonso, Department of Neurology, 3200 SW 60th Court, Suite 302, Miami, FL $33155)$.

COMMENT. The electroclinical events thought to be characteristic of benign familial neonatal convulsions (BFNC) are nonspecific. BFNC is heterogeneous in clinical and EEG features and cannot be distinguished from benign infantile familial convulsions on the basis of clinical seizure patterns. (see Progress in Pediatric Neurology III, 1997;pp8-9).

Outcome of neonates with electrographically identified seizures was correlated with background EEG and number of independent seizure foci in a study of 53 neonates at Sydney Children's Hospital, Australia (Bye AME et al. Pediatr Neurol April 1997;16:225-231). A severely depressed EEG background in a neonate with seizures or at risk of seizures was correlated with mortality during the first month, and frequent neonatal independent seizure foci correlated with poor outcome at 1 year.

\section{HANDICAPS ASSOCIATED WITH EPILEPSY}

The prevalence and severity of handicaps in 217 children and adolescents with epilepsy were assessed at the University of Goteborg, Ostra Hospital, Sweden, using the World Health Organization International Classification of Impairments, Disabilities and Handicaps (ICIDH). Major additional disorders occurred in 113 (52\%), mental retardation (MR) in 106 and cerebral palsy (CP) in 48 children. Motor and sensory disabilities, involving locomotion, arm and hand function, were common even in children unaffected by CP or MR. Handicap, defined as a disadvantage, resulting from a disability or impairment, adversely affected physical independence and orientation, correlated with epilepsy duration and secondary generalization, and was relieved by epilepsy surgery. (Beckung E, Uvebrant P. Impairments, disabilities and handicaps in children and adolescents with epilepsy. Acta Paediatr March 1997;86:254-260). (Respond: Dr E Beckung, Department of Paediatrics, University of Goteborg, Ostra Hospital, S-41685 Goteborg, Sweden).

COMMENT. Children with epilepsy complicated by cerebral palsy or mental retardation are diagnosed and treated early for their associated disabilities and handicaps. Those with epilepsy unassociated with CP or MR 